\title{
UNA APROXIMACIÓN AL CAMPO DE ESTUDIO DEL PENSAMIENTO ESTRATÉGICO DESDE LAS PUBLICACIONES ACADÉMICAS: DE LO PREDECIBLE A LO EMERGENTE*
}

\author{
PAULA ANDREA LÓPEZ LÓPEZ"* \\ UNIVERSIDAD CENTRAL (BOGOTA, COLOMBIA)
}

Recibido/Received/Recebido: 03/10/2011 - Aceptado/ Accepted/Aprovado: 27/02/2013

\begin{abstract}
Resumen
En las última dos décadas, diversos autores del management han realizado un llamado a reflexionar sobre el paradigma dominante en el campo de estudio de la estrategia. Las críticas se han centrado en el enfoque determinístico con el que se ha tratado el problema estratégico, planteando la necesidad de cuestionar el modelo racional-mecanicista imperante y de proponer nuevos postulados que sean congruentes con las condiciones actuales del mundo de las organizaciones. En ese sentido, el presente artículo es una revisión bibliográfica sistemática que pretende, no solo señalar, los elementos que configuran el pensamiento estratégico en los últimos años, sino que a su vez reconocer las características de la perspectiva emergente que se ha ido consolidando en el campo. Palabras clave: Pensamiento estratégico, Estrategia, Estrategia empresarial, Enfoques estratégicos.
\end{abstract}

\section{AN APPROXIMATION TO THE STRATEGIC THINKING STUDY FIELD FROM ACADEMIC PUBLICATIONS PERSPECTIVE: FROM THE PREDICTABLE TO THE EMERGENT.}

\begin{abstract}
In the last two decades, various management authors have encouraged thoughts about the dominant paradigm in the strategy field. Critics have focused on the deterministic approach which has been used to deal with the strategic problem, establishing the necessity to question the prevailing mechanistic-rational model and propose new principals consistent with the current world conditions of organizations. In that sense, the present article is a systematic literature review that not only aims to point out the configuration of the strategic thinking elements in recent years, but also to recognize the characteristics of the emerging perspective that has been consolidated in the field.

Keywords: Strategic thinking, Strategy, Business strategy, Strategic approaches.
\end{abstract}

El documento es resultado de las líneas de investigación que adelanta la autora en la Universidad Central de Bogotá (Colombia). Administradora e Empresas de la Universidad Nacional de Colombia (Manizales), Maestra en Administración de la Universidad Naconal de Colombia (Bogotá). Correo electrónico: plopez@ucentral.edu.co 


\title{
UMA APROXIMAÇÃO AO CAMPO DE ESTUDO DO PENSAMENTO ESTRATÉGICO A PARTIR DAS PUBLICAÇÕES ACADÊMICAS: DO PREVISÍVEL AO EMERGENTE
}

\begin{abstract}
Resumo
Nas últimas duas décadas, diversos autores do management fizeram um chamado a refletir sobre o paradigma dominante no campo de estudo da estratégia. As críticas se centraram no enfoque determinístico com o que se tratou o problema estratégico, propondo a necessidade de questionar o modelo racional-mecanicista imperante e de propor novos postulados que fossem congruentes com as condições atuais do mundo das organizações. Nesse sentido, o presente artigo é uma revisão bibliográfica sistemática que pretende não só assinalar os elementos que configuram o pensamento estratégico nos últimos anos, mas também reconhecer as características da perspectiva emergente que se foi consolidando no campo.

Palavras chave: Pensamento estratégico, Estratégia, Estratégia empresarial, Enfoques estratégicos.

López, P. (2013) Una aproximación al campo de estudio del pensamiento estratégico desde las publicaciones académicas: De lo predecible a lo emergente. En: Revista de la Facultad de Ciencias Económicas de la Universidad Militar Nueva Granada. rev.fac.cienc.econ, XXI (1).
\end{abstract}

JEL: M14, M21.

\section{Introducción}

\author{
"Una nueva teoría estratégica menos \\ geométrica y más hermenéutica, menos \\ racional y más relacional"
}

(Pérez, 2007).

El pensamiento estratégico es trasversal a la gestión y se constituye en el medio que permite la trasformación y conducción de organizaciones a estados superiores, posibilitando la construcción del futuro, disponiendo los medios y mecanismos necesarios para su arquitectura. En ese orden de ideas, el pensamiento estratégico se ha convertido en la preocupación central de quienes tienen a su cargo organizaciones y de igual manera de quienes están involucrados en los procesos de formación de los gestores.

Tradicionalmente cuando se hace referencia al pensamiento estratégico se evocan las corrientes propuestas desde las escuelas anglosajonas de Administración, quienes han realizado grandes aportes a dicho campo, constituyéndose de alguna manera en el enfoque preponderante, tanto para su aplica- ción en las organizaciones como para la formación. La perspectiva anglosajona tradicional está fundamentada en la idea del proceso racional, deliberado, programado de la formulación estratégica, hace énfasis en la predicción y el control.

En la actualidad las organizaciones se encuentran inmersas en entornos altamente cambiantes y competitivos, donde reina la no linealidad, el dinamismo, la incertidumbre, el pensamiento estratégico se convierte en ese medio para enfrentar de manera consciente esa volatilidad del entorno. Razón por la cual los enfoques tradicionales con los que se ha abordado se vuelven insuficientes para responder a las condiciones de un nuevo orden económico, social, político y cultural al que se enfrentan las organizaciones. Lo que de alguna manera ha conducido a reflexionar acerca del paradigma en el que se funda el pensamiento estratégico imperante; con el propósito de encontrar una perspectiva que responda a la complejidad inherente a las organizaciones de la actualidad.

El presente artículo es producto de la revisión bibliográfica sistemática de un conjunto de artículos, capítulos de libros y libros, que abordan diversas aproxi- 
maciones teóricas sobre estrategia. El estudio es de corte comprensivo, desde una aproximación cualitativa y documental; tiene como propósito identificar las características del pensamiento estratégico de los últimos 20 años, y reconocer la existencia de nuevos enfoques para abordar el campo de estudio.

Dentro de los hallazgos se puede destacar la tendencia generada desde mediados de los años 90 de configurar las perspectivas de abordaje del campo, en escuelas o corrientes de pensamiento claramente diferenciadas en su concepción, propósitos y herramientas. De igual manera es importante señalar que la revisión de la literatura académica permitió establecer la evolución del campo de estudio en relación a la concepción de la estrategia (propósitos y áreas de conocimiento involucradas), en los aspectos metodológicos que la sustentan (métodos y herramientas), en los actores que intervienen en el proceso; en los factores considerados (incertidumbre, poder, cultura, ambiente, entre otros). Aspectos que de alguna manera han conducido a la configuración de un paradigma emergente que responde a las condiciones actuales de los procesos estratégicos en las organizaciones.

El documento se encuentra estructurado en tres partes: En la primera se realiza una conceptualización alrededor de los términos pensamiento estratégico y estrategia como referente conceptual del estudio. En la segunda se presentan los aspectos metodológicos que enmarcaron la revisión bibliográfica sistemática, así como la técnica de interpretación bibliográfica utilizada (Atlas Ti). En la tercera parte se realiza la discusión de los hallazgos desde tres tópicos: clasificación en escuelas, enfoques de las perspectivas del campo de estudio, características del pensamiento estratégico en el periodo de la revisión y paradigma emergente.

\section{Un marco conceptual: el pensamiento estratégico y la estrategia}

En la disciplina administrativa es común encontrar imprecisiones conceptuales en los términos que le son propios ${ }^{1}$, razón por la cual muchos de ellos son usados como sinónimos o de manera indistinta en diversos contextos. En particular en el campo de estudio de la estrategia suelen utilizarse como términos con el mismo significado, pensamiento estratégico y estrategia ${ }^{2}$. Bien podría decirse que la abundante literatura académica del campo, que crece a una tasa exponencial, poco se ha preocupado por el uso adecuado de la terminología, lo que acentúa aún más la falta de distinción entre los conceptos. Dentro del marco del presente trabajo, pensamiento estratégico y estrategia, sí bien se entienden como conceptos interrelacionados y complementarios, representan distintos sentidos en la dinámica organizacional.

La conceptualización alrededor del término pensamiento estratégico no es tan común en los textos o artículos del campo, ha existido una orientación mayor hacia la definición de términos como estrategia, planeación estratégica, dirección estratégica, entre otros.

Ohmae $(1983,16)$ es uno de los primeros autores que logro hacer la precisión del término, y define pensamiento estratégico como la "combinación de métodos analíticos y elasticidad mental utilizados para obtener ventajas competitivas". Morrisey (1997, 13) concibe el pensamiento estratégico como "la coordinación de méritos creativos dentro de una perspectiva común que permite a una organización avanzar hacia el futuro de manera satisfactoria". Por su parte Mintzberg, Ahlstrand \& Lampel (1998) consideran que pensar estratégicamente significa la forma como los gerentes, directivos y demás miembros de una organización usan las ideas y conceptos para entender e interpretar los objetivos y circunstancias en torno a la organización. Para Román $(2010,27)$ pensamiento estratégico "es una actitud de vida basada en la reflexión que desemboca en un actuar que cimienta el futuro de la empresa".

Conceptos como administración, gestión, gerencia y dirección.

Incluso en algunos casos se usan en el mismo sentido los términos planeación estratégica, diagnóstico estratégico y proceso estratégico. 
Al entrar a revisar los conceptos se puede ver, que en su mayoría sugieren la idea de futuro como la intención que lo hace pertinente. Algunas definiciones centran la atención en los aspectos que se deben considerar para construir ese futuro, y en otros casos la forma en la que se relacionan los actores que intervienen en él se convierte en el eje del concepto. Es pertinente señalar, que en la propuesta de dichos conceptos se deja de lado la noción de pensamiento y la de estrategia, elementos centrales en la formación del constructo. En consecuencia y para poder aproximarse a la definición de pensamiento estratégico, es relevante abordar la conceptualización desde una precisión conceptual, que permita responde a las preguntas ¿Qué es pensamiento?, ¿Qué es estrategia? y finalmente ¿Qué es pensamiento estratégico?

\section{1. ¿Qué es Pensamiento?}

El ejercicio del pensamiento es un proceso central del ser humano, bien podría decirse que las acciones o actividades que realiza el hombre están mediadas por la capacidad de pensar. Existen diversas maneras de aproximarse a la noción de pensamiento, las cuales se plantean en relación con la forma como emerge. Desde la perspectiva de Dewey (1989) las distintas maneras de pensar encuentran su pertinencia en la capacidad que tiene dicho pensamiento de facilitar la acción. El autor presenta cuatro significados que se le han otorgado al término pensamiento (Dewey, 1989, 23-26): El primero de ellos está relacionado con la corriente de ideas que pasan por la mente, hecho que de alguna manera es autónomo, no está regulado y es permanente en el ser humano. El segundo significado limita esta actividad a las cosas que no se perciben directamente a través de los sentidos $^{3}$, se trata de una construcción mediada por el acto de imaginar, pero que requiere coherencia en los episodios imaginativos. Un tercer significado se asocia con la creencia - creo cual o tal cosa-, es decir, con el hecho de acoger ideas de otros incluso de manera inconsciente. La creencia se acepta por- que es común, por tradición, instrucción e imitación, no porque se haya participado activamente en su formación o se haya indagado sobre la misma. El cuatro significado es denominado pensamiento reflexivo caracterizado porque persigue un propósito o una finalidad, lo que le da sentido y enmarca una cadena de ideas que lo conforman.

Dewey (1989) plantea que la noción de pensamiento reflexivo, precisa la actividad de pensar, de alguna manera los demás significados conducen a confundir el pensamiento con otros procesos mentales del ser humano. En ese sentido el autor plante que el pensamiento reflexivo procura:

"Una ordenación secuencial de ideas en la que cada una de ellas no sólo es determinada por la anterior, sino que a su vez determina a la siguiente dando lugar a una conclusión temporal; cada conclusión remite a las que la precedieron apuntando siempre a una conclusión definitiva” (Dewey, 1989, 22).

El pensamiento reflexivo persigue un objetivo y ese objetivo impone una tarea que controla y organiza la secuencia de ideas. Desde la perspectiva de Dewey (1989) este tipo de pensamiento nos acerca al mundo real, trata de huir de la distracción, de la especulación banal. No se habla de una verdad definitiva como resultado del proceso de reflexión, sino de la necesidad de poner en tela de juicio las creencias temporales para continuar analizando los fundamentos sobre los que se sostienen durante el proceso de construcción. En consecuencia, el pensamiento reflexivo llevaría a adoptar diferentes concepciones para averiguar qué sucedería en cada caso; se trata de un encadenamiento ordenado de ideas.

De alguna manera se podría plantear que lo que "constituye el pensamiento reflexivo es el examen activo, persistente y cuidadoso de toda creencia o supuesta forma de conocimiento a la luz de los fundamentos que la sostienen y las conclusiones a las que tienda" (Dewey, 1989, 24).

3 Que no se ve, ni se oyen, ni se tocan, ni se saborean, ni se huelen (Dewey, 1989). 
Hay tres fases por las que atraviesa el pensamiento reflexivo (Dewey, 1989, 28-30): parte de un estado de duda o de dificultad mental, de conflicto inicial, de situación a resolver, que suscita la actividad del pensamiento, para dar paso a un proceso de búsqueda, de investigación racional, con el fin de encontrar alguna información que esclarezca la duda de la que se parte. Se indagaran las posibles causas del fenómeno abordado para, finalmente, llegar a una conclusión que arroje luz sobre el interrogante que desencadenó el proceso reflexivo y permita actuar. En consecuencia, el pensamiento reflexivo procura resolver un problema, darle respuesta a una situación o superar una dificultad. Por ende toda posibilidad de respuesta, conclusión, o propuesta que surge, es puesta a prueba con el ánimo de revisar sí satisface el propósito que le dio origen y sí conduce a la acción.

\section{2. ¿Qué es Estrategia?}

En cuanto al concepto de estrategia, éste ha sido abordado por diversidad de autores, desde distintas perspectivas, razón por la cual proliferan las definiciones y no existe una concepción universalmente aceptada. Las primeras referencias al concepto en el campo de la gestión ${ }^{4}$, se remontan a los años 60's y 70's con autores como Chandler (1962), Ansoff (1965), y Andrews (1971).

Chandler (1962) concibió la estrategia como la determinación de metas y objetivos básicos de largo plazo de la empresa, la adición de los cursos de acción y la asignación de recursos necesarios para lograr dichas metas. Para Ansoff (1965) es el vínculo entre las actividades de la organización y las relaciones producto/mercado, que define la naturaleza básica de sus negocios en el presente y el futuro, la estrategia permite entonces la dialéctica de la empresa con su entorno. Por su parte Andrews (1971), la define como la determinación conjunta de objetivos de la organización y de las líneas de acción para alcanzarlas.
El concepto se relacionó inicialmente con la determinación de los objetivos o propósitos de la organización y de las líneas de acción para alcanzarlos. De igual manera se definió como el medio para delimitar en qué clase de negocio se encuentra la organización o en cuál quiere estar, para puntualizar qué clase de organización es o quiere ser y para establecer el carácter de la contribución económica o de otra índole que busca dar a la sociedad (Andrews, 1971).

En los años siguientes florecieron gran cantidad de conceptos en la literatura de gestión, entre otros, Tabatorny \& Jarniu $(1975,45)$ apuntan que es "el conjunto de decisiones que determinan la coherencia de las iniciativas y reacciones de la empresa frente a su entorno". Schendel \& Hoffer (1978) señalan que estrategia concierne a las características básicas de la relación y de la velocidad de respuesta que una organización realiza con su entorno. Michael Porter $(1980,65)$ defiende la idea de estrategia como "la respuesta, sobre la base de las capacidades, y recursos de la organización, a las oportunidades y amenazas del entorno, para mantener una diferenciación que a su vez se convierta en ventaja competitiva”. Según Menguzzatto \& Renau (1991, 76) la estrategia empresarial "explícita los objetivos generales de la empresa y los cursos de acción fundamentales, de acuerdo con los medios actuales y potenciales de la empresa, a fin de lograr la inserción de ésta en el medio socio económico". Harper \& Linch $(1992,18)$ proponen que la estrategia está encaminada a "establecer un sistema dinámico de anticipación en el que se destacan y agrupan los aspectos estratégicos diferenciadores empresariales en el marco de un entorno abierto, procurando desarrollar una cultura empresarial que se apoye en las ventajas competitivas que la empresa tiene". Ohmae (1995, 57) explica que es "el comportamiento con el que una corporación se diferencia positivamente de sus competidores, usando los puntos fuertes relativos de la corporación para satisfacer mejor las necesidades del consumidor".

4 Desde una perspectiva histórica, inicialmente la estrategia se relacionó con la sabiduría militar, teniendo como sentido el encuentro de contrarios y se remonta a los griegos, quienes usaban el término strategikós para designar el mando que hacía un general de su ejército. En el campo económico fue introducido en el año 1944 por Von Newman y Morgerstern. 
Para Mintzberg (1990) estrategia, puede tomar diversas formas a las que dio el nombre de las ' 5 P', estas son: plan, pauta, patrón, posición y perspectiva. De igual manera, plantea dos perspectivas en las que se forma la estrategia, la deliberada (reflexión a priori) y la emergente (construida a posteriori).

La estrategia, desde la perspectiva de Etkin (2003, 134) "es un concepto que se refiere a la necesidad y voluntad de enfrentar no sólo lo inesperado (el momento), sino también lo desconocido". Además este autor señala que las estrategias son decisiones complejas porque sintetizan o contienen muchas otras decisiones. Se toman desde una mirada amplia (no parcializada), en la cual se conjugan y articulan factores políticos, económicos y sociales $e$ implican tomar una posición que compromete y moviliza múltiples áreas de la organización.

Dada la diversidad de definiciones de estrategia, algunos trabajos intentan establecer puntos de convergencia conceptual. Se destacan los esfuerzos por determinar la estructura, dimensiones y evolución histórica del concepto en los estudios de Bracker (1980), Feurer \& Chaharbaghi (1995), Boyd, Gove \& Hitt (2005), Fréry (2006), y Furrer, Thomas \& Goussevskaia (2007), que presentan un estudio cienciométrico a partir de regularidades en definiciones de dirección estratégica. Sumado a estos, Ramos-Rodriguez \& Ruiz-Navarro (2004) y Nerur, Rasheed \& Natarajan (2008), enfocan sus esfuerzos en análisis bibliométricos del campo. Finalmente, Ronda \& López (2008) presentan un interesante estudio de la estructura de la relación entre definiciones del concepto mediante el análisis de redes sociales, el estudio se basa en 38 conceptos de estrategia elaboradas entre 1962-2003. Su principal conclusión es que existe un alto nivel de dispersión en la perspectiva teórica del concepto e identifica visiones diferentes en la definición, así como en los aspectos que consideran esenciales los autores.

\section{3. ¿Qué es pensamiento estratégico?}

Las precisiones conceptuales presentadas en los dos acápites anteriores, pueden conducir a una definición de pensamiento estratégico. Pero antes es necesario señalar que la propuesta que se plantea parte de una relación recursiva, sí así pudiera llamarse, entre pensamiento y estrategia. Se conciben como conceptos inseparables, uno requiere del otro para su generación, por ende no es simple definir la frontera entre uno y otro. La estrategia requiere de pensamiento, de ahí surge, pero a su vez el pensamiento necesita de la estrategia para hacer posible la acción. En consecuencia, las estrategias pertinentes son las que emergen en conjunto con el pensamiento estratégico, no las que se eligen de un grupo de opciones predeterminadas ${ }^{5}$, promovidas en la mayoría de literatura académica del campo. La estrategia no es una receta, ni mucho menos una forma mágica de sencilla aplicación, como tan poco lo es el pensamiento estratégico.

Derivado entonces de la noción presentada de pensamiento reflexivo, y concibiendo la estrategia como un mecanismo que conduce a la acción, se propone el siguiente concepto de pensamiento estratégico: la capacidad del ser humano de situar a la organización en una perspectiva futura, a partir de la interrelación de las condiciones del ambiente con su identidad, intereses, capacidades y recursos; lo que permite diseñar alternativas de acción que conduzcan a la construcción de la apuesta de futuro.

El pensamiento estratégico está circunscrito al mundo de las organizaciones, debe responder a los intereses de un colectivo, aunque puede emerger de un individuo. Por tanto, no existe un pensamiento estratégico único, éste se encuentra mediado por la experiencia de los individuos, por su manera de percibir y comprender el mundo, así como por las características y condiciones de la organización. Lo que conduce a reconocer que cada organización se

5 Tipología de estrategias: estrategias ofensivas o de crecimiento, estrategias defensivas; estrategias concéntricas, estrategias genéricas. 
enmarca en un conjunto de circunstancias que la hacen única y que configuran su finalidad, naturaleza e identidad, y es a partir de ahí que se define la propuesta de futuro. De igual manera comprender la organización como un sistema dinámico complejo, lo que implica enfrentar los problemas o situaciones que le atañen de forma tal que la propuesta surja de una visión compleja, dado que el contexto organizacional está conformada por un conjunto de relaciones, de encadenamiento de factores, que se influyen y condicionan mutuamente, no existe una trayectoria lineal, los procesos avanzan y retroceden, en un movimiento continuo.

El pensamiento estratégico permite establecer $\mathrm{co}^{-}$ nexiones entre los factores que afectan las organizaciones (condiciones del ambiente, identidad, intereses, capacidades y recursos, entre otros), cada conexión que establezca el individuo y el colectivo crea una nueva perspectiva, lo que conduce a diseñar acciones diferenciadoras dentro de la misma dinámica organizacional. Lo que involucra un grado de razonamiento analítico, sin embargo no hay que anclarse en él, se trata de procurar por un pensamiento que se explicite a través de la acción, que propenda por mejorar la capacidad de generar alternativas viables para concretar la apuesta de futuro, reconociendo también el papel de los procesos no racionales que están presentes en todo acto de conocer y crear, como es la intuición.

El pensamiento intuitivo implica el acto de captar el significado, el alcance o la estructura de un problema o situación sin confiar explícitamente en el razonamiento o análisis (Bruner, 1968). Se encuentra relacionado más con la participación del subconsciente y de la percepción sensorial, y permite romper con las respuestas aprendidas y darle paso a la posibilidad de ver lo nuevo, lo distinto y captar su significado. En este sentido, Minztberg (1998) plantea que en la formación de la estrategia deben darse relaciones de complementariedad entre el pensamiento intuitivo y el razonamiento analítico. El primero da lugar a la originalidad y a la innovación; el segundo permite contextualizar las ideas originales y estructurarlas en un curso de acción que va tomando forma en una realidad concreta (Minztberg, 1998).
La finalidad del pensamiento estratégico es dar respuesta a una situación con un conjunto de alternativas de acción que deben ser puestas en relación con un propósito de futuro y con los resultados que se esperan alcanzar. En esa medida se encuentra asociado a la toma de decisiones de un individuo en pro de un colectivo, para lo que se requiere de la integración entre intuición y razón. El pensamiento estratégico no debe estar limitado al pensamiento analítico, pero tampoco puede basarse exclusivamente en el pensamiento intuitivo.

Quienes dirigen las organizaciones en la actualidad, se encuentran ante el gran reto de pensar para decidir y actuar, de elegir la opción más adecuada y el modo de acción que permita su logro. El pensamiento estratégico se constituye entonces, en el medio que posibilita esa unión indispensable entre pensar y actuar, por ende es fundamental para la intervención de organizaciones. Permite conducirlas a estados superiores a partir de la comprensión de la diversidad de factores que están en juego a la hora de construir su futuro apoyándose para ello en la estrategia, que se convierte en su mecanismo de materialización.

\section{Aspectos metodológicos}

El presente trabajo es de corte comprensivo, más que predictivo o explicativo; desde una aproximación cualitativa y documental (artículos, capítulos de libros, libros). Para su realización se adoptaron dos metodologías: i) Revisión bibliográfica sistemática y ii) Análisis de contenido.

La revisión bibliográfica sistemática, permite dar respuesta a una pregunta o conjunto de preguntas por medio de la exploración de la producción bibliográfica que se ha elaborado alrededor de un campo de conocimiento (libros, artículos, periódicos, entre otras). Existen diversas aproximaciones en relación a los pasos a seguir para realizar una revisión bibliográfica sistemática (Berelson, 1952; Krippendorf, 1990; Creswell, 2003; Gratton \& Jones, 2004), de manera general se identifican las siguientes fases: i) Definición de los propósitos de la revisión y campo de estudio, ii) Selección de fuentes de información y criterios de búsqueda iii) Realización de la búsqueda, 
iv) Depuración de resultados, y v) Análisis e interpretación de resultados.

\section{1) Propósitos}

La presente revisión se enfocó en dos propósitos fundamentales: i) establecer las características del pensamiento estratégico de los últimos 20 años, ii) identificar la existencia de nuevos enfoques para abordar dicho campo de estudio. A continuación se relacionan los aspectos definidos para la revisión.

\section{2) Origen de los datos}

Las fuentes de información fueron artículos de revistas indexadas internacionales reconocidas en campo, así como bases de datos especializadas:

- Bases de datos Scielo

- Academy of Management Journal

- Academy of Management Review

- Administrative Science Quarterly

- Strategic Management Journal

- California Management Review

- Harvard Business Review

- Mit Sloan Management Review

- Colecciones bibliográficas

- Academy of Management Publications

- European Management Review

- Management Decision

- International Journal of Management

- Journal of Management Development

- Journal of Bussines

\section{3) Palabras de búsqueda}

Estrategia, Estrategia Empresarial, Estrategia corporativa, Pensamiento estratégico, Planeación estratégica, Proceso estratégico

Se realizó la búsqueda de las palabras clave tanto en idioma inglés como en español, utilizando los conectores lógicos Y-AND, O-OR, así como la palabra central entre paréntesis para priorizar la búsqueda - ejemplo: (strategy AND business)- De igual ma- nera se utilizó el conector NOT, que permite la exclusión de términos en la búsqueda (ejemplo: strategy AND business) NOT manufacturing.

Periodo de la búsqueda: 2000-2011.

\section{4) Resultados de la búsqueda y criterios de selección de documento}

Tabla 1. Relación de documentos encontrados por fuente de información ${ }^{6}$

\begin{tabular}{|c|c|c|c|c|}
\hline $\begin{array}{l}\text { Fuentes de } \\
\text { Información }\end{array}$ & $2000-2005$ & $2006-2010$ & 2011 & Total \\
\hline $\begin{array}{l}\text { Academy of Manage- } \\
\text { ment Publications }\end{array}$ & 19 & 24 & 3 & 46 \\
\hline $\begin{array}{l}\text { Administrative } \\
\text { Science Quarterly }\end{array}$ & 9 & 18 & 4 & 31 \\
\hline $\begin{array}{l}\text { Strategic Manage- } \\
\text { ment Journal }\end{array}$ & 12 & 29 & 6 & 47 \\
\hline $\begin{array}{l}\text { European Manage- } \\
\text { ment Review }\end{array}$ & 14 & 17 & 4 & 35 \\
\hline $\begin{array}{l}\text { Management De- } \\
\text { cisión }\end{array}$ & 7 & 11 & 2 & 20 \\
\hline $\begin{array}{l}\text { International Journal } \\
\text { of Management }\end{array}$ & 9 & 16 & 1 & 26 \\
\hline $\begin{array}{l}\text { Journal of Manage- } \\
\text { ment Development }\end{array}$ & 7 & 14 & 3 & 24 \\
\hline Journal of Bussines & 14 & 23 & 6 & 43 \\
\hline $\begin{array}{l}\text { California Manage- } \\
\text { ment Review }\end{array}$ & 7 & 12 & 3 & 22 \\
\hline $\begin{array}{l}\text { Harvard Business } \\
\text { Review }\end{array}$ & 25 & 37 & 9 & 71 \\
\hline $\begin{array}{l}\text { Base de datos } \\
\text { SCIELO }\end{array}$ & 13 & 21 & 6 & 40 \\
\hline TOTAL & 136 & 222 & 47 & 405 \\
\hline
\end{tabular}

A continuación se presentan los criterios establecidos para la selección de la producción académica y bibliográfica a ser tenida en cuenta en el análisis ${ }^{7}$.

6 Fuente: Elaboración propia.

7 Es importante señalar que no en todos los casos fue posible acceder a los textos completos de los artículos, lo que impido su inclusión en el análisis. 
Tabla 2. Relación de criterios de inclusión y exclusión ${ }^{8}$

\begin{tabular}{|l|l|}
\hline \multicolumn{1}{|c|}{ Inclusión } & \multicolumn{1}{c|}{ Exclusión } \\
\hline $\begin{array}{l}\text { Artículos que presenten aproxima- } \\
\text { ciones teóricas sobre estrategia. }\end{array}$ & $\begin{array}{l}\text { Artículos sobre la aplicación de } \\
\text { los conceptos de estrategia a áreas } \\
\text { particulares de la empresa como } \\
\text { marketing, finanzas, operaciones, } \\
\text { recursos humanos, entre otras. }\end{array}$ \\
\hline $\begin{array}{l}\text { Artículos que realicen disertacio- } \\
\text { nes teóricas. }\end{array}$ & $\begin{array}{l}\text { Artículos con aplicaciones puntua- } \\
\text { les de herramientas de diagnóstico } \\
\text { estratégico o estudios de caso. }\end{array}$ \\
\hline $\begin{array}{l}\text { Artículos que realicen propuestas } \\
\text { metodológicas para el abordaje } \\
\text { del tema. }\end{array}$ & Reseñas de libros. \\
\hline $\begin{array}{l}\text { Artículos que presenten resultados } \\
\text { de investigaciones cuantitativas y } \\
\text { cualitativas que planteen propues- } \\
\text { tas teóricas o metodológicas. }\end{array}$ & $\begin{array}{l}\text { No contar con el artículo en texto } \\
\text { completo, aunque cumpliera los } \\
\text { criterios de inclusión. }\end{array}$ \\
\hline
\end{tabular}

Dada la abundante literatura académica encontrada y teniendo en cuenta los criterios de inclusión y exclusión se seleccionaron 37 artículos para el análisis de contenido y lectura de 20 libros de los autores más representativos del campo.

\section{5) Técnica de interpretación bibliográfica- análisis de contenido}

Se realizó un análisis cualitativo de los artículos seleccionados, mediante la técnica de análisis de contenido, con el propósito de identificar los rasgos distintivos de los discursos sobre estrategia, así como reconocer el surgimiento de nuevas aproximaciones.

El análisis de contenido es una técnica de investigación para la descripción objetiva, sistemática del contenido manifiesto de distinto tipo de comunicaciones o documentos (Berelson, 1952). Según Krippendorf (1990), se hace con el fin de formular, a partir de contenidos de comunicación, inferencias reproducibles y válidas que puedan aplicarse al contexto en el cual se interpretan.

En el presente trabajo la interpretación de los documentos seleccionados se realizó rastreando la respues- ta a dos preguntas transversales ¿Cuáles son las características que identifican el pensamiento estratégico de los últimos años? ¿Existen enfoques o propuesta emergentes en el campo de estudio de la estrategia?

Para el procesamiento de los textos se utilizó el programa Atlas Ti (The Qualitative Data Analysis Software), que posibilitó el análisis y codificación de la información, facilitando la sistematización y la interpretación. El procedimiento para el análisis de contenido se relaciona a continuación:

- Análisis inicial de contenido directo con la ayuda de una lectura previa consistente en la primera revisión del material a analizar (artículos, capítulos de libros, libros), a partir del cual se identificarán las principales categorías analíticas.

- Análisis cualitativo inductivo que contiene tres pasos:

- Codificación abierta en primer plano, códigos y categorías para hallar respuestas específicas, significados y sentidos similares o acuerdos dentro de los artículos, capítulos de libros, libros.

- Codificación en segundo plano, códigos y temas, que permite identificar frecuencias de respuestas a las preguntas orientadoras, con el propósito de generalizar, agrupar o establecer la dispersión entre las mismas.

- Identificación de categorías centrales con las que se establece la aproximación conceptual, sintetizando la información recolectada, sistematizada y analizada.

\section{Discusión}

\subsection{Clasificación en escuelas o enfoques de las perspectivas del campo de estudio}

Uno de los hallazgos de la revisión, fue identificar que desde mediados de los años 90 se generó una tendencia a clasificar los diversos postulados del campo de estudio de la estrategia en escuelas, enfoques o vertientes.

La propuesta de las distintas taxonomías se realiza con el propósito de explicar los postulados que

8 Fuente: Elaboración propia. 
fundamentan la estrategia. El sentido de la mayoría de las clasificaciones pretende responder exclusivamente a la pregunta ¿cómo surge la estrategia?. Sin embargo, existen propuestas más amplias como la de Whittington (2002), y Mintzberg, Ahlstrand \& Lampel (1998), autores que enmarcan su tipificación desde tres componentes centrales: el sentido teológico de la estrategia, sus orígenes (deliberado, emergente) y los actores involucrados.

La identificación de la orientación hacia clasificar la aproximación a la estrategia en escuelas de pensamiento, también permite evidenciar como son entendidos dos procesos que se han definido como fundamentales en el campo: la formulación y la implementación. Desde distintos enfoques se conciben como dos procesos que van de la mano, pero que se generan en momentos distintos, se separa el pensamiento de la acción. Mientras otras posturas logran integrarlos en la práctica, considerando que son procesos inseparables, buscando una construcción compleja del mismo.

Es necesario señalar que la pertinencia de un enfoque u otro, depende de que dicha postura reconozca o no que en la actualidad las organizaciones se mueven en ambientes inestables, con múltiples interacciones que se deben identificar y comprender, con el fin de actuar con respecto a ellas y transformarlas para el beneficio de la organización. Los estrategas deben desenvolverse en condiciones donde lo único certero que ofrece el entorno es la incertidumbre, los altos niveles de riesgo y la complejidad. En consecuencia, los ambientes actuales tienen características con las que no se enfrentaron los estrategas del siglo pasado y presentan condiciones que suponen nuevos retos, a los que primordialmente debe dar respuesta el pensamiento estratégico.

A continuación se hace una breve presentación de algunas de las distintas clasificaciones de estrategia que se precisaron a partir de la revisión bibliográfica (Tabla 3).

Dentro de los trabajos que se orientan a establecer clasificaciones se encuentra la propuesta de Martinet (1996, 1997), quien concibe la estrategia desde los puntos de vista teleológico, sociológico, ideológico y ecológico. La perspectiva teleológica pone el énfasis en los objetivos de la organización, en su concepción y la forma como la organización los alcanza en el tiempo. Lo sociológico permite la comprensión de los diferentes actores que hacen parte del proceso estratégico, tanto interno como externo, quienes formulan las estrategias y llevan a cabo acciones que de ellas se derivan. Desde lo ideológico se enmarca el espíritu del discurso estratégico, y su influencia, tanto en el orden organizacional como en la sociedad en general. Finalmente, en el punto de vista ecológico se identifican los elementos del entorno como el mercado, o los grupos externos de interés, el ambiente y su relación con la organización (Martinet, 1996, 1997).

Otra perspectiva es la de Carrance (1986) y Ramanantsoa (1997) que plantean la clasificación en dos escuelas: racionalista y conductista. La primera que privilegia aproximaciones racionales, promueve una absoluta confianza en las capacidades cognitivas del estratega, principalmente, la razón. La estrategia es concebida como un producto del análisis desde la lógica de la utilidad y permite adecuar las acciones de las organizaciones a los fines que se han previsto desde su interior. Desde la otra perspectiva, vinculada al pensamiento behaviorista, se incorpora en el análisis a los diferentes actores de la organización y al entorno. La estrategia surge como resultado de las presiones de los agentes externos y la interacción de los actores internos. En este sentido, la organización es vista como un sistema abierto cuyas transformaciones sucesivas, por ende sus estrategias, son dependientes de los cambios en el ambiente (Carrance, 1986; Ramanantsoa, 1997).

Surge también la propuesta de Whittington (2002) quien plantea la existencia de 4 escuelas de la estrategia, la clásica, la evolutiva, la procesualista y la sistémica. Los cuatro enfoques se construyen a partir de las respuestas que surgen a dos preguntas fundamentales que se plantea el autor (Whittington, 2002, 2): ¿para qué sirve la estrategia y cómo se diseña?

La escuela clásica responde al enfoque más antiguo del campo, nace en los años 60 y se ha convertido en el de mayor influencia. Su propuesta se enmarca dentro de los métodos racionales de planificación, 
Tabla 3. Escuelas de estudio de la estrategia9

\begin{tabular}{|c|c|c|c|c|c|}
\hline AUTOR & \multicolumn{5}{|c|}{ ESCUELAS/ENFOQUES } \\
\hline $\begin{array}{c}\text { MARTINET } \\
(1996 \text { y 1997) }\end{array}$ & $\begin{array}{l}\text { Punto de vista } \\
\text { Teleológico }\end{array}$ & $\begin{array}{l}\text { Punto de vista } \\
\text { Sociológico }\end{array}$ & $\begin{array}{l}\text { Punto de vista } \\
\text { Ideológico }\end{array}$ & \multicolumn{2}{|c|}{ Punto de vista Ecológico } \\
\hline $\begin{array}{c}\text { CARRANCE (1986) y } \\
\text { RAMANANTSOA (1997) }\end{array}$ & \multicolumn{2}{|c|}{ Escuela Cognitiva } & \multicolumn{3}{|c|}{ Escuela Conductista } \\
\hline $\begin{array}{l}\text { WHITTINGTON } \\
\qquad(2002)\end{array}$ & Escuela Clásica & Escuela Evolucionista & Escuela Proces & & Escuela Sistémica \\
\hline $\begin{array}{c}\text { VAN DER HEIJDEN } \\
(1998)\end{array}$ & Escuela Racionalista & Escuela Evolutiva & Escuela Proce & & \\
\hline $\begin{array}{l}\text { MINTZBERG, AHLSTRAND, \& } \\
\text { LAMPEL (1998) }\end{array}$ & $\begin{array}{l}\text { Escuelas prescriptivas } \\
\text { (Diseño, Planeación, } \\
\text { Posicionamiento) }\end{array}$ & $\begin{array}{r}\text { Escuelas descriptivas (Es) } \\
\text { Cultur }\end{array}$ & $\begin{array}{l}\text { empresarial, Cognitiv } \\
\text { der y Ambiental) }\end{array}$ & dizaje, & $\begin{array}{c}\text { Escuela transformativa o de } \\
\text { la configuración }\end{array}$ \\
\hline
\end{tabular}

donde priman los cálculos y los análisis deliberados (Whittington, 2002). Dentro de esta perspectiva se considera la planificación como el medio para lograr el objetivo principal de las organizaciones: la maximización de la rentabilidad. La escuela se caracteriza por la separación entre concepción y ejecución de la planificación, en consecuencia, es competencia del Director de la organización la toma de decisiones estratégicas, y se parte de la confianza en la asertividad de la toma de decisiones (Whittington, 2002). Por tanto la estrategia es una construcción deliberada, que tiene como objetivo primordial la maximización de beneficios.

El enfoque evolucionista reconoce la incapacidad de generar estrategias desde el interior y básicamente propone que la organización está a la deriva del entorno externo y no de sus propias capacidades. Se parte de la concepción que es el mercado quién define la estrategia, se "confía menos en la habilidad del director para planear y actuar de manera racional" (Whittington, 2002, 19), su rol es fundamental en la identificación de amenazas, puesto que el principal objetivo es la supervivencia. La estrategia entonces debe permitir estar lo mejor preparados posible para las exigencias actuales del entorno y surge como producto de la selección del mercado (Whittington, 2002).

La escuela procesualista considera que "tanto las organizaciones como los mercados son fenómenos complicados y caóticos de los que surgen las estrategias" (Whittington, 2002, 25). Por ende reducen radicalmente la importancia del análisis racional y

9 Fuente: Elaboración propia a partir de Martinet (1996, 1997); Carrance (1986); Ramanantsoa (1997); Whittington (2002); Van Der Heijden (1998); Mintzberg, Ahlstrand, \& Lampel (1998). 
centran su atención en el aprendizaje continuo y en el acoplamiento de los intereses y comportamientos internos de la organización y del entorno. La estrategia es emergente, se va construyendo en términos del aprendizaje y a partir del reconocimiento de la complejidad del ser humano, siendo el resultado la maximización de beneficio su otro tipo de objetivos (Whittington, 2002). Para los procesualistas la estrategia implica negociación mediante la formación de coaliciones que reflejan los intereses en juego de la organización.

Desde la perspectiva del enfoque sistémico "las razones que guían la estrategia son particulares de un contexto sociológico concreto" (Whittington, 2002, $25)$. Se tiene una visión relativista, reconociendo que los objetivos y medios que constituyen la estrategia están ligados a los sistemas sociales particulares en los que se desarrolla. Este enfoque se centra en la consideración del contexto cultural, entendiendo que la estrategia es sensible al fenómeno sociológico, haciendo énfasis en que no todas las culturas tienen los mismos criterios de éxito. En ese sentido los objetivos de la estrategia y el modo de diseñarla están intrínsecamente relacionados con la sociedad en la que está inmersa la organización por ende el estratega (Whittington, 2002).

Van der Heijden (1998) concibe el pensamiento estratégico bajo 3 escuelas: racionalista, evolutiva y procesual. La escuela racionalista, separa el pensamiento de la acción y se funda en la idea de una solución óptima, que se encuentra a partir de un proceso racional. En este sentido el trabajo del estratega consiste en acercarse a la posible solución óptima, en el marco de la limitación de recursos con los que cuenta la organización. "El estratega piensa en nombre de la organización entera, y desarrolla la estrategia óptima como un proceso de buscar la máxima utilidad entre varias opciones" (Van der Heijden, 1998, 37).

La perspectiva de la escuela evolucionista, se enmarca en un sentido distinto al de los racionalistas y consideran que la estrategia tiende a evolucionar en conjunto con los factores internos y externos que afectan la organización. La propuesta de esta escuela considera que la toma de decisiones es un proceso que requiere ajustes y negociaciones, para que la organización logre actuar de manera coherente. La escuela guarda relación con los postulados de la teoría del caos y la complejidad, y que considera que en tiempos de turbulencia en el entorno no tiene gran sentido tratar de racionalizar la estrategia y el mundo es demasiado complejo para controlarlo (Van der Heijden, 1998).

La escuela procesualista supone que el éxito empresarial requiere una invención original, debido a que la incertidumbre tiene el efecto de desplazar la clave del éxito de la estrategia óptima al proceso estratégico más hábil. La organización necesita comprometerse en un proceso para hacer espacio a las ideas, a la capacidad mental de las personas. Cualquier idea inventiva que pueda mejorar el enlace entre las competencias organizacionales y el entorno empresarial, necesita aflorar y considerarse. Según los procesualistas la estrategia desencadena la entrada a un ciclo de aprendizaje, el cual enlaza y desarrolla gradualmente la percepción, la comprensión, el pensamiento y la acción. El ciclo de aprendizaje se basa en la idea de un desarrollo gradual continuo, por lo que integra experiencia, desarrollo de sentido y acción en un solo fenómeno holístico (Van der Heijden, 1998).

Mintzberg, Ahlstrand \& Lampel en 1998 presentan un estudio comprensivo de la estrategia que les permite clasificar el campo en diez escuelas diferentes. Las primeras tres escuelas (diseño o concepción, planeación y posicionamiento) son agrupadas bajo el título de escuelas normativas o prescriptivas, caracterizadas por la formulación antes de la implementación; las siguientes seis escuelas (del espíritu empresario o entrepreneurial, cognitiva, aprendizaje, cultural, poder y ambiental) son reunidas en el conjunto de las escuelas descriptivas, ya que se enfocan en el contenido de la estrategia y la formación estratégica, en vez de la formulación, que da paso a la estrategia emergente. Y finalmente, la escuela transformativa o de la configuración, la cual intenta adaptar la estrategia a cualquiera de las escuelas anteriores, según el contexto.

La escuela del diseño remonta sus orígenes a Selznick (1957) y Chandler (1962), y es una de las 
más influyentes, fuente de los cursos en estrategia que han estudiado el famoso FODA (fortalezas, oportunidades, debilidades, amenazas). La evaluación de fortalezas y oportunidades (al interior de la organización), a la luz de debilidades y amenazas (del medio ambiente en general), lo cual propone un modelo de estrategia que busca alcanzar correspondencia o encaje entre las capacidades internas y las posibilidades externas. El modelo básico para la formulación de estrategias parte entonces del análisis externo e interno de la organización, asumiendo que del conjunto de estrategias resultantes del proceso una es mejor opción para ser implementada, una vez se encuentre formulada por completo. La escuela es consistente con los principios clásicos de racionalidad (al diagnóstico sigue la prescripción y sólo entonces llega la acción), por ende se separa el pensamiento de la acción (Mintzberg, Ahlstrand \& Lampel, 1998).

La escuela de la planificación, ha sido alabada y también cuestionada por amplia literatura especializada en el campo. El mensaje central que propone es pronosticar las condiciones futuras para actuar sobre ellas, construyendo las estrategias formalmente, por medio de un procedimiento explícito, entrenamiento determinado, análisis formal y fundamento numérico. La estrategia debe ser guiada por un cuadro de planificadores altamente educados, parte de un departamento especializado en planeación estratégica con acceso directo al ejecutivo jefe. Se propone un modelo básico de planeación que comprende 6 etapas: i) fijación de objetivos, ii) verificación externa, iii) verificación interna, iv) evaluación de la estrategia, y v) puesta en operación de la estrategia y vi) fijar plazos para todos el proceso (Mintzberg, Ahlstrand \& Lampel, 1998).

Enfatizando la importancia de las estrategias en sí mismas, la escuela del posicionamiento se enfocó en el contenido de las estrategias (Mintzberg, Ahlstrand \& Lampel, 1998). Esta escuela afirma que sólo unas pocas estrategias clave, en la forma de posiciones en el mercado, pueden defenderse de los competidores presentes y futuros. Es decir, que las empresas que consiguieran esas posiciones obtendrían ganancias más altas que las que no, lo que a su vez garantizaba una reserva de recursos adicional para la expansión y consolidación (Porter, 1980). Siguiendo esa lógica se pudo definir un número limitado de estrategias básicas genéricas para las distintas industrias. La formación de la estrategia seguía siendo un proceso consciente, controlado, que producía estrategias deliberadas completamente desarrolladas que debían explicitarse antes de ser formalmente implementadas (Mintzberg, Ahlstrand \& Lampel, 1998).

En la escuela entrepreneurial, la responsabilidad de la formación de la estrategia se deposita en los dictados del "líder", haciendo énfasis en los estados mentales y procesos tales como institución, juicio, sabiduría, experiencia y perspicacia (Mintzberg, Ahlstrand \& Lampel, 1998). Asocia una imagen y sentido de la dirección llamado "visión", que sirve al líder de inspiración y consistencia de lo que debe ser hecho. La estrategia entrepreneurial es deliberada en sus líneas y sentido de dirección, y emergente en sus detalles, para que pueda adaptarse en función de la experiencia. Schumpeter (1947), introduce la noción de destrucción creativa, donde el entrepreneur es la persona que lleva a cabo nuevas combinaciones más apropiadas de los medios de producción. Knight (1967) define la labor del entrepreneur como sinónimo de manejo de alto riesgo. Cole (1959) menciona cuatro clases de entrepreneur, el inventor calculador, el innovador inspirador, el promotor optimista y el constructor se una empresa sólida. En esta escuela se debilitaban las fortalezas del planeamiento y la visión comenzó a ganar fuerza en la formulación de la estrategia.

La escuela cognitiva analiza la formación de estrategias como un proceso mental, lo que hace necesario indagar la mente del estratega, es decir, entrar en el campo de la psicología cognitiva. La escuela intenta investigar el proceso de pensamiento de la estrategia, desarrollando estructuras de conocimientos y procesos de pensamiento por la experiencia directa, que da forma a lo que se sabe y es consecuentemente materia de lo que se hace, dándole forma a la experiencia. Las estrategias entonces emergen como perspectivas, en la forma de conceptos, mapas, esquemas o marcos, que determinan la forma en que la gente maneja los mensajes del entorno (Mintzberg, Ahlstrand \& Lampel, 1998, 220). 
Las estrategias emergen en la escuela del aprendizaje, cuando las personas actuando individualmente o colectivamente, aprenden sobre una situación y la capacidad de la organización de tratar con ésta, lo esencial es saber cómo se forman las estrategias en las organizaciones, no cómo se formulan. En consecuencia, la formación de la estrategia es un proceso de aprendizaje en el tiempo en el cual no hay separación entre formulación e implementación, en el que es usual que el aprendizaje sea colectivo (Mintzberg, Ahlstrand \& Lampel, 1998). La escuela inicia con un artículo de Lindblom (1959) "la ciencia de arreglárselas" quien elaboro un conjunto de ideas bajo el título de incrementalismo inconexo. Sin embargo Quinn (1980) señaló la ruta de lo que se llama escuela del aprendizaje, con el concepto de incrementalismo lógico.

Caracterizando la formación de la estrategia como un proceso manifiesto de influencia, la escuela del poder enfatiza en el uso de la negociación para favorecer intereses particulares. El poder describe el ejercicio de influenciar más allá de lo económico y de la convencional competencia de mercado, las relaciones de poder rodean las organizaciones y también las permean. El "micro" poder se ocupa de los juegos políticos internos y el "macro" poder de los que juega la organización (Mintzberg, Ahlstrand \& Lampel, 1998). La formación de la estrategia depende entonces del poder y la política, interna y externa, por ende la estrategia tiende a ser emergente.

La escuela cultural se funda en la idea del interés común, que entretejen un conjunto de individuos en una entidad integrada llamada organización. Desde esta perspectiva la formación de la estrategia es un proceso cuyo núcleo es la fuerza social de la cultura, un proceso de interacción social, basado en las creencias e ideas compartidas por los miembros de una organización. Las creencias compartidas son reflejadas en tradiciones y hábitos, así como manifestaciones tangibles como relatos, símbolos, construcciones y productos (Mintzberg, Ahlstrand \& Lampel, 1998, 337). El concepto ideología, tan importante para este enfoque, describe un conjunto fuerte de creencias compartidas intensamente por los miembros de la organización.

El entorno en sí mismo se presenta a la organización en la escuela ambiental como un conjunto de fuerzas generales, como un actor central en el proceso de elaboración de estrategias. La tendencia de este enfoque es considerar a la organización como una entidad pasiva que sólo reacciona ante un entorno que fija la agenda (Mintzberg, Ahlstrand \& Lampel, 1998). Las organizaciones se agrupan en nichos de tipo ecológico, posiciones donde permanecen hasta que los recursos se vuelvan escasos o las condiciones muy hostiles, entonces ellas mueren. La estrategia debe responder a estas fuerzas o de lo contrario expulsarlas.

El mensaje central de la escuela de configuración es aplicar cada uno de los enfoques anteriores en su contexto y tiempo, integrando la esencia de cada una de las demás escuelas, en consecuencia se entiende la estrategia como un proceso de transformación. Si una organización adopta una configuración determinada, la formación de la estrategia es el proceso de pasar de una configuración a otra, es decir, de transformarse (Mintzberg, Ahlstrand \& Lampel, 1998). Las estrategias resultantes de la transformación estabilizan la dirección de la organización, pero son ocasionalmente y apreciablemente interrumpidas para efectuar una transición a una nueva estrategia. Los "estados" o características estratégicas que son exitosas pueden ser ordenados en secuencias de patrones, que sostengan cierta estabilidad o al menos una adaptabilidad en el cambio estratégico (Mintzberg, Ahlstrand \& Lampel, 1998).

Las diversas clasificaciones presentadas anteriormente no solo dejan ver las orientaciones tradicionales que se han aplicado en el estudio de la estrategia, sino que a su vez permiten evidenciar los nuevos elementos que se han ido incorporando los últimos años al campo, y que de alguna manera han promovido el surgimiento de enfoques (cultura, ambiente, poder, aprendizaje, entre otras), que pueden romper con la mirada tradicional de la estrategia, desde sus fines, la forma de construirla y los actores involucrados. 


\subsection{Características del pensamiento estratégico}

La revisión bibliográfica permite identificar que en los textos y artículos, aún sigue imperando la concepción de los orígenes de la estrategia empresarial. Entendida como un mecanismo que permite definir los objetivos de las organizaciones, así como los medios para alcanzarlos. De igual manera la idea de competencia y de ganar posiciones en el mercado a través de un conjunto de acciones también continúa presente, motivo por el cual la estrategia resulta ser, exclusivamente, un medio para alcanzar los fines económicos de las organizaciones.

Es importante destacar que la década de los noventa se constituye en la época de consolidación del campo de la estrategia. Sin embargo, la literatura académica también muestra como desde mediados de la década se pone de manifiesto los problemas de la planeación estratégica, uno de los enfoques y herramientas más utilizados. Derivado entre otras de las consideraciones de autores como Ansoff (1987), Ansoff \& Sullivan (1993) quien defiende el paso de la planeación estratégica a la gerencia estratégica, así como la emergencia de un nuevo paradigma en el campo; dado no solo al posible agotamiento del enfoque sino también a sus limitantes para responder a condiciones cambiantes. Mintzberg (1994) en un sentido similar señala tres falacias del procesos de planeación: i) Falacia de la predeterminación, ii) Falacia de la separación, iii) Falacia de la formalización y la "gran falacia" que consiste en no haber denominado la planeación estratégica como "programación estratégica", promovida como un proceso para formalizar que dejó de lado el pensamiento estratégico.

Wilson $(1994,13)$ por su parte logró establecer los sietes pecados capitales de la planeación estratégica: i) El personal se hizo cargo de la planeación, ii) El proceso dominó al personal, iii) Los sistemas de planeación estaban diseñados para no producir ningún resultado, iv) La planeación se centró en el juego de las fusiones, adquisiciones y desinversiones a expensas del desarrollo del negocio principal, v) Los procesos de planeación no lograron desarrollar verdaderas alternativas estratégicas, vi) La planeación descuido los requisitos organizacionales y culturales de la estrategia, y vii) La previsión fue poco apropiada para planificar en una era de reestructuración $e$ incertidumbre.

A raíz de las restricciones que la planeación estratégica mostró, se empiezan a incorporar en el pensamiento estratégico variables sociopolíticas y culturales relacionadas con la empresa, dejando de lado no solo la mirada estática de la estrategia, sino también desplazando los análisis meramente cuantitativos. Cobran entonces mayor protagonismo el liderazgo, la cultura, los recursos humanos, la información y la comunicación. Particularmente en los artículos desarrollados recientemente, se logra distinguir que se concibe la estrategia más allá que el simple establecimiento de planes y comienza a ser determinantes las fases de ejecución, los actores que están involucrados, los recursos y capacidades con que se cuenta. La estrategia deja pensarse como un medio exclusivo para el logro de mayores ganancias y empieza a configurarse como un mecanismo que permite la consolidación interna de la organización y su diferenciación en el mercado.

La revisión de los documentos seleccionados, permitió además identificar que en los últimos 10 años se han acentuado las críticas por el énfasis en los cálculos racionales y análisis deliberados con los que se basa la formulación de la estrategia. De igual manera, la predominancia de una visión limitada, desde las ciencias económicas, que obstaculizan su acción en la creciente complejidad del entorno. Lo que de alguna manera ha conducido a que recientemente se hayan integrado al campo otras áreas del conocimiento como la biología, la sociología, la antropología, la ciencia política e incluso la psicología, desplazando la idea de la única finalidad economicista de la estrategia. La preocupación por ejemplo, por las externalidades negativas de las acciones estratégicas está a la orden de día para quienes se encuentran a cargo de las organizaciones. El acercamiento a disciplinas como la biología, la sociología, la antropología, la psicología, la ciencia política, permiten una mejor comprensión de las acciones humanas, como lo son las estrategias empresariales. Desde una perspectiva interdisciplinar es posible generar una orientación de pensamiento estratégico que pueda percibir e inte- 
rrelacionar la diversidad de factores que entran en juego al momento de decidir y actuar en función de los rumbos estratégicos de las organizaciones.

En ese orden de ideas otro aspecto que se logró rastrear es el abandono, en los últimos años, de la idea de linealidad, fragmentación, reduccionismo y determinismo que ha imperado, reconociendo que el proceso de pensamiento estratégico no es lineal, que no puede basarse en la pretensión de control y mucho menos en la eliminación de la incertidumbre, porque el futuro no es posible predecirlo. En ese sentido, si bien se siguen reconociendo los resultados financieros en la estrategia, su finalidad se centra en que es un medio que permite actuar frente a lo incierto e impensado. Los cambios vertiginosos a los que se ven abocadas las organizaciones y que se deben tener presentes en el proceso de formación de la estrategia, no son predecibles y mucho menos controlables.

Una de las características más reconocidas en el campo de estudio de la estrategia, se refiere a su formación ¿Las estrategias son deliberadas o emergentes?. Sin el ánimo de precisar que la revisión permitió encontrar un consenso al respecto, se pueden señalar dos aspectos:

- Hasta mediados de los años 90, la mayoría de autores de estrategia hacían alusión a un proceso estratégico deliberado en procura de la predicción y el control. Perspectiva tradicional, que responde al modelo racional-mecanicista, donde la tesis central es la de pronosticar las condiciones futuras para actuar sobre ellas, construyendo las estrategias formalmente, por medio de un procedimiento explícito, un análisis formal y con fundamento numérico. Es de esta manera como se construye la estrategia deliberada, a través de un modelo formalizado que comprende 5 etapas: evaluación externa, evaluación interna, creación de la estrategia, evaluación y elección de la estrategia y aplicación de la estrategia.

- $\mathrm{Al}$ incorporarse el concepto de incertidumbre y complejidad al campo, sobretodo en la última década, se reconoce que la formación de la estrategia se encuentra mediada por un proceso que en la mayoría de ocasiones es emergente, sujeto a las condiciones particulares del momento y asociado a la naturaleza e identidad de la organización, por lo cual no puede pensarse como un proceso formal, explícito y que predetermina sus resultados.

En ese sentido la estrategia se encuentra asociada más con la idea de lo flexible, lo cambiante y emergente, que con lo programado o predeterminado, tiene que ver más con el aprendizaje y la adaptación que con la manera de dar respuesta a un plan formalizado.

En lo que se refiere a los actores involucrados en el proceso de formación de estrategia, la revisión deja ver que aunque en sus inicios (años 60 y 70) el actor principal y responsable del proceso era el alto directivo, considerando la formulación estratégica como un ejercicio erudito por excelencia y bajo esa perspectiva de carácter exclusivo de los altos directivos. El auge de la planeación estratégica, dio origen a nuevos actores denominados "planificadores", quienes estaban encargados de realizar análisis y diagnósticos estratégicos, así como de proveer información al directivo responsable de definir la estrategia, perspectiva que se profundizó en los años 90 y que desde la postura de algunos autores se sigue conservando en la actualidad.

Sin embargo y como se señaló anteriormente, los cambios del entorno, las nuevas demandas de mercado, el aumento de la competencia, así como la diversidad de organizaciones, condujo a involucrar diversos y nuevos actores en el proceso estratégico. Las propuestas de los documentos que hacen alusión a la necesidad de reconocer la necesidad de intervención de otros actores en el proceso, se sustentan en la idea que la estrategia requiere de la interacción de los miembros que conforman las organizaciones, así como de la integración de los fines corporativos y los fines personales, para poder construir un propósito compartido que reconozca distintas miradas, intereses y propósitos, lo que permite disponer la organización para su logro. De igual manera hacen referencia a las elecciones estratégicas, donde juegan un papel determinante los valores, aspiraciones e ideales de quienes la conci- 
ben, la cultura de la organización, así como el reconocimiento de las expectativas de los accionistas y de los demás sectores de la sociedad con los que se interactúa, lo que conduce necesariamente a una perspectiva colectiva del proceso, que se aparta de planteamiento con el que surge la estrategia en los años 60 centrada fundamentalmente en los intereses de los accionistas y de quienes se encuentran a cargo de la dirección de las organizaciones.

La revisión de las características del pensamiento estratégico, a partir de la literatura académica producida en los últimos años, permite reconocer aquellos elementos que se siguen manteniendo en la actualidad y que están asociados a su origen, configurándose como la permanencia de los postulados de la escuela clásica o tradicional. De igual manera permite evidenciar la evolución que ha tenido en relación a la concepción de la estrategia (propósitos y áreas de conocimiento involucradas), en los aspectos metodológicos que la sustentan (métodos y herramientas), en los actores que intervienen en el proceso; en los aspectos considerados (complejidad, incertidumbre, poder, cultura, ambiente, entre otros). Lo que muy seguramente esta allanando el camino que conduce a una transformación del paradigma que ha enmarcado la aproximación al campo de estudio de la estrategia empresarial.

\section{3. ¿Surge un nuevo paradigma en el campo de estudio de la estrategia?}

La revisión bibliográfica permitió reconocer los cuestionamientos realizados por distintos autores (Hart, 1992; Prahalad \& Hamel, 1994; Mintzberg, 1994, 1998; Sotirin \& Tyrell, 1998; Ansoff, 1987, Ansoff \& Sullivan, 1993; Stacey, 2000; Pettigrew, Thomas \& Whittington, 2001; Pérez, 2004, 2007; Ezzamel \& Willmott, 2004; French, 2009), al paradigma imperante en el campo. Las discusiones se derivan por un lado de las profundas transformaciones $^{10}$ que se han generado en distintos ámbitos de la sociedad (económico, político, social, cultural) que reclaman formas distintas de aproximación, $y$ por otro, a la necesidad de actuar bajo esa nueva lógica y de responder a retos incluso desconocidos que enfrentarán las organizaciones del siglo XXI.

La reflexión de dichos autores se ha centrado en el hecho que la mayoría, sino todos, de los desarrollos tanto teóricos como metodológicos del pensamiento estratégico se han construido bajo los conceptos de orden, disyunción, reducción, jerarquización, determinismo ${ }^{11}$. Conceptos que son limitados para comprender y desenvolverse en el medio actual donde no existen dinámicas predecibles ni continuas, por el contrario lo habitual es enfrentarse a lo incierto e inesperado.

Derivado entonces, de la pérdida de importancia de conceptos como orden, estabilidad y control frente a los de desorden, interacciones, inestabilidad, diálogo, aprendizaje, autoorganización, como fuente de pensamiento estratégico, se requiere una nueva forma de construirlo desde las teorías que lo fundamentan como de las herramientas en las que se apoya. No se puede perder de vista que la inestabilidad, la incertidumbre y la complejidad caracterizan los entornos actuales, por ende cada vez es más difícil diagnosticar, predecir y planificar como se ha venido haciendo. Las formas tradicionales de pensamiento estratégico son insuficientes para responder a estos retos, sus modelos racionales no ofrecen en la actualidad sensitividad al tiempo y al entorno, ni pueden sugerir novedosas formas de actuar (Tsoukas \& Knudsen, 2002).

Se plantea entonces, la necesidad de repensar el paradigma imperante de pensamiento estratégico, lo que obliga a reflexionar sobre aspectos tanto de orden teórico como metodológico. Basado en la propuesta de Pérez (2004, 2007), se presentan cinco cambios fundamentales, que se consideran están configurando una nueva perspectiva para el pensamiento estratégico.

\footnotetext{
10 Globalización, desarrollo de las tecnologías de la información y comunicación, cambio en los sistemas de producción y comercialización, inestabilidad política, aumento del desempleo, surgimiento de nuevos bloques económicos, entre otros.

11 Concepciones heredadas de la lógica cartesiana que influenciado el conocimiento desde el siglo XVII.
} 
Tabla 2. Cambios que requiere un nuevo paradigma en el campo de estudio de la estrategia ${ }^{12}$

\begin{tabular}{|l|l|}
\hline \multicolumn{1}{|c|}{ CAMBIO } & \multicolumn{1}{c|}{ CONSECUENCIA } \\
\hline $\begin{array}{l}\text { Cambio en el paradigma cen- } \\
\text { tral: de la fragmentación a la } \\
\text { complejidad }\end{array}$ & $\begin{array}{l}\text { Asumir la creciente complejidad del } \\
\text { mundo, verlo como una trama fluida } \\
\text { que sigue dinámicas no siempre li- } \\
\text { neales. }\end{array}$ \\
\hline $\begin{array}{l}\text { Cambio en el sujeto: del actor } \\
\text { racional al hombre relacional. }\end{array}$ & $\begin{array}{l}\text { Trabajar con seres humanos (relacio- } \\
\text { nales) y no con actores (racionales). }\end{array}$ \\
\hline $\begin{array}{l}\text { Cambio en la idea de organiza- } \\
\text { ción: de unidad de producción } \\
\text { a centro de interrelaciones. }\end{array}$ & $\begin{array}{l}\text { Pensar las organizaciones como } \\
\text { sistemas complejos. Fijarse en los } \\
\text { flujos y en las interconexiones, ahí } \\
\text { donde surgen las relaciones y las } \\
\text { innovaciones. }\end{array}$ \\
\hline $\begin{array}{l}\text { Cambio en el enfoque de pensa- } \\
\text { miento estratégico: del conflicto } \\
\text { a la articulación. }\end{array}$ & $\begin{array}{l}\text { Proponer un enfoque dialogante me- } \\
\text { diante la articulación adecuada de las } \\
\text { percepciones plurales de los sujetos } \\
\text { involucrados. }\end{array}$ \\
\hline $\begin{array}{l}\text { Cambio en las herramientas: } \\
\text { los nuevos instrumentos para } \\
\text { hacer pensar estrategias en un } \\
\text { mundo complejo y dinámico. }\end{array}$ & $\begin{array}{l}\text { Usar métodos capaces de describir } \\
\text { la complejidad, las interacciones, los } \\
\text { flujos, las relaciones en red de los } \\
\text { sistemas no lineales como las orga- } \\
\text { nizaciones. }\end{array}$ \\
\hline
\end{tabular}

\subsubsection{Cambio en el paradigma central: de la simplicidad a la complejidad}

Uno de los principales y grandes cambios que debe producirse es el del paradigma central en el que se ha fundado el pensamiento estratégico, es decir, transitar de la simplicidad a la complejidad.

Tradicionalmente se ha identificado el pensamiento estratégico con el análisis, la fragmentación, la disyunción, el determinismo, características de la simplicidad. De un paradigma que privilegia el orden en el universo, y persigue el desorden; ve a lo uno y ve lo múltiple, pero no puede ver que lo uno puede al mismo tiempo ser múltiple. La simplicidad separa lo que está ligado (disyunción), o bien unifica lo que es diverso (reducción) y estas dos lógicas son mutilantes (Morin, 2001).
La visión imperante desde el paradigma de la simplicidad ha conducido a que los expertos en el campo del pensamiento estratégico, inspirados por esa mentalidad racionalista, hayan privilegiado los cálculos sobre la imaginación y la transformación. Los estrategas de alguna manera se han dedicado a fragmentar la realidad, el problema, la oportunidad, y a tratar después sus propiedades por separado (Pérez, 2007). Pero las grandes transformaciones del siglo XX y de inicios del XXI, la velocidad de los avances tecnológicos, así como el surgimiento de nuevas ramas de la ciencia, han puesto de manifiesto la necesidad de reconocer que la realidad es compleja y que en vez de fraccionarla, el hombre puede comprenderla y actuar en ella. Es preciso falsear la idea que "la realidad se puede desarmar para estudiar el comportamiento de las partes por separado, y que es posible luego proceder a reconstruir la conducta global a partir de las partes" (Etkin \& Schvarstein, 2005, 83). Es necesario entonces aproximarse al pensamiento estratégico desde la complejidad.

En el marco de este trabajo la complejidad ${ }^{13}$ es entendida a partir de la propuesta de Morin (2001, $32)$, la cual se encuentra relacionada directamente con pensamiento complejo, y es entendida como: "Un tejido (complexus: lo que está tejido en conjunto) de constituyentes heterogéneos inseparablemente asociados: presenta la paradoja de lo uno y lo múltiple [...] es, efectivamente, el tejido de eventos, acciones, interacciones, retroacciones, determinaciones, azares, que constituyen nuestro mundo fenoménico”.

Desde esta perspectiva, el paradigma de la complejidad proporciona el marco conceptual para el pensamiento complejo (Delgado \& Sotolongo, 2006; Morin, 2001, 2007). El pensamiento complejo implica otro modo de concebir y pensar el universo que no busca complicar, sino abrir la mente hacia otros conceptos y progresar hacia la comprensión de lo complejo. Y esta comprensión de lo complejo implica reconocer y comprender la ambigüedad, la

12 Fuente: Adaptado de Pérez (2004, 2007).

13 No existe una única definición del término complejidad, de hecho las definiciones se han propuesto desde diversas áreas del conocimiento, evidenciando que se trata de un concepto multidisciplinar. Incluso autores hacen referencia a ciencias de la complejidad (Maldonado, 2003). 
contradicción, la no trivialidad, la policausalidad, la autopoiésis, la auto-organización, la falta de precisión, y la impredecibilidad (López \& Mariño, 2010). La complejidad considera en efecto que los fenómenos del universo están caracterizados por un conjunto de fuerzas contradictorias y complementarias que se ejercen en él y sobre él (Morin, 2001).

En consecuencia, el pensamiento estratégico como un suceso que emerge en las organizaciones responde a una lógica compleja. En esa medida se requiere abandonar la idea de linealidad, fragmentación, reduccionismo y determinismo que ha imperado, reconociendo que el proceso de pensamiento estratégico no es lineal, que no puede basarse en la pretensión de control y mucho menos en la eliminación de la incertidumbre, porque el futuro es intrínsecamente impredecible e incierto. El pensamiento estratégico debe procurar por no basarse exclusivamente en el pensamiento formal-analítico, deliberado y programado, cuya metodología se basa en la repetición, en la concepción que predominan en los comportamientos deterministas, como sí las organizaciones funcionaran bajo la lógica de una máquina trivial, no como los sistemas complejos que son. Es indispensable reconocer que el "proyecto estratégico de una organización indefectiblemente está inserto en una realidad compleja, cuya interacción es imposible de controlar" (Manucci, 2006, 23).

El pensamiento estratégico desde la complejidad no se presenta como una receta para conocer y poder actuar frente a lo inesperado, se le otorga más bien el sentido de: Un método de conocimiento, que rechaza ser reducido a un enfoque mecanicista, balístico y objetivo, confinado en una programación detallada, pero que se inscribe, al contrario en el rico paradigma de la acción social compleja, es decir, de la interacción entre sujetos dotados de representaciones, de poderes, de intenciones y de contextos diferentes (Martinet, 1996, 367).

En ese orden de ideas, quienes piensen estratégicamente una organización deben estar orientados a movilizar y construir la mirada de futuro partiendo de su contexto, de la interrelación de los sujetos que participan y de las nuevas formas que surgen de la interacción. De igual manera es necesario vincular los diversos intereses en juego, así como reconocer la variedad de comportamientos que puede tener el entorno con sus condiciones y exigencias. Desde esta perspectiva el pensamiento estratégico posibilita:

- La construcción de una visión global e integral de la organización, entendiéndola como una realidad compleja que no puede ser comprendida e intervenida de manera fragmentada.

- La creación de la organización a futuro, no como un programa deliberado, sino como una respuesta emergente a las circunstancias que la rodean.

- La incorporación de los elementos más relevantes de su realidad interna, así como los requerimientos y restricciones del entorno, aumentando su capacidad de comprensión y acción.

- La adopción de una mirada desde la complejidad para el pensamiento estratégico, se traduce en un nuevo y cambiante marco de relaciones entre los actores que intervienen en él: directivos, colaboradores, clientes, proveedores, sociedad. Lo que indefectiblemente conduce al segundo cambio, la concepción de sujeto.

\subsubsection{Cambio en la concepción de sujeto: del actor racional al hombre relacional}

La forma de pensar y actuar del estratega, ha sido tradicionalmente enmarcada bajo el ideal de racionalidad y de eficientísimo. Lo que de alguna manera ha conducido a que se privilegien las técnicas y herramientas, excluyendo al ser humano como actor principal del proceso; incluso se considera que puede ser reemplazado por constructos reduccionistas y economicistas (software estadístico, herramientas econométricas, simuladores de decisión), que producen respuestas exactas y rápidas, por consiguiente más eficientes. A pesar de los renombrados trabajos ${ }^{14}$ que han cuestionado el supuesto de hombre económico racional, el campo del pensamiento estratégico continúa con

14 Herbert Simon, en los años 50 fue uno de los primeros en criticar la idea de racionalidad. De igual manera Daniel Kahnemann, premio Nobel (2002), también desvirtuó el supuesto de racionalidad de los actores sociales. 
ésta pretensión, y solo se procura por la búsqueda de una única solución óptima (estrategia) que tenga como fin último mayores resultados económicos.

Se puede evidenciar entonces, que se ha perdido de vista que más allá de las herramientas y de los cálculos sofisticados, el pensamiento estratégico es producto de la acción humana. Por ende, involucra razones y emociones, incoherencias, contradicciones, subjetividades, percepciones, miedos, expectativas e intereses propios del ser humano (Pérez, 2007), y no posee la tan anhelada exactitud matemática. Es imperativo apartarse de a esa visión limitada y racional de ser humano para asumir una nueva concepción desde el sujeto relacional. Lo que implica enfocarse en los procesos cognitivos y de conocimiento, en las interrelaciones de los actores, en aspectos de orden cultural, y en la diversidad de elementos que confluyen en el surgimiento del pensamiento estratégico de una organización. Continuar fomentando una perspectiva que no reconoce la complejidad del ser humano, que procura reducir al máximo sus emociones y que pretende simplificarlo bajo un esquema racional, es aferrase a un enfoque que limita y que no permite la toma de decisiones estratégicas acordes al contexto.

También se requiere explorar la necesidad de una mirada interdisciplinar, ya que "ninguna disciplina aislada dispone del conocimiento requerido para pensar la estrategia" (Pérez, 2007, 10). El acercamiento a disciplinas como la biología, la sociología, la antropología, la psicología, la ciencia política, que nos permiten una mejor comprensión de las acciones humanas, pero que han sido arrinconadas por algunas corrientes de la Administración y de la Economía. Desde una perspectiva interdisciplinar es posible generar una orientación de pensamiento estratégico que en primera medida se centre en el ser humano, que además pueda percibir e interrelacionar la diversidad de factores que entran en juego y finalmente, que no solo sea aplicable a los negocios, como se privilegia, sino a todos los campos de la actividad humana.

Las técnicas e instrumentos, los cálculos racionales, no podrán reemplazar la capacidad humana de pen- sar, aprehender y actuar en la complejidad del mundo. Es en definitiva desde el ser humano de donde emerge el pensamiento estratégico, y a partir de allí se orientan las acciones para construir organizaciones económicamente viables dentro de un proyecto de sociedad. Se vuelve indispensable entonces "no plantearse más la cuestión del qué hacer ignorando la cuestión del sujeto. Todo lo que niega el sujeto mutila irremediablemente nuestra visión de la realidad humana" (Morin, 1993, 76).

\subsubsection{Cambio en la idea de organización: de unidad de producción a sistema social}

Los desarrollos iniciales del campo del pensamiento estratégico concentraron su mirada exclusivamente en las organizaciones de tipo empresarial, como centros de producción y generación de lucro. Con una perspectiva funcionalista y mecanicista, donde existe una desagregación de la organización en áreas funcionales, de manera que se entiende a la totalidad como la suma de funciones de mercadeo, finanzas, producción y recursos humanos, en el marco de la jerarquía y la centralización.

La introducción de la teoría general de sistemas a la disciplina administrativa y la influencia reciente del paradigma de la Complejidad, condujeron a la adopción de una visión de las organizaciones como sistemas sociales, donde las interacciones, la emergencia, la innovación, son entre otras, las características de sus dinámicas. Esta visión ha permitido reconocer y promover procesos que no se podían explicar desde el mecanicismo, entender que las organizaciones como sistemas complejos, evolucionan, que es necesario fijarse en los flujos y en las interconexiones, ahí donde surgen las relaciones y la innovación (Pérez, 2007).

En ese sentido, tiende a perderse la idea de organizaciones como estructuras jerárquicas, estáticas, donde directivos racionales adoptan decisiones centralizadas siguiendo secuencias preestablecidas, con el único propósito de aumentar la productividad. Dando paso a la idea de sistema social, donde priman las interrelaciones entre seres humanos, entre estos y los demás componentes de la organización, entre la organización y su entorno. 
Asumir la posición de las organizaciones como un sistema social, hace pensar en las características que le son propias. De acuerdo con Navarro (2000, 137) las organizaciones se "caracterizan por su inestabilidad inherente, por la presencia de fenómenos autoorganizados, por la predominancia de procesos de carácter no lineal y por la importancia de elementos de azar en la determinación de sus futuros, futuros, por otra parte, imprevisibles". Las organizaciones como sistemas alejados del equilibrio, inestables, no lineales, regidos por la incertidumbre, no responden de la misma manera a los mismos estímulos. Lo que conduce a no aspirar a la aplicación de recetas o formulas preestablecidas para su intervención, sino a reconocer su naturaleza e identidad y a partir de ahí construir la mejor forma de actuar desde su contexto.

Esta visión de organización cuestiona la forma tradicional que ha predominado para la construcción del pensamiento estratégico, enmarcado en un proceso de alguna manera determinista, concebido en una secuencia de fases claramente definidas y basado en un conjunto de matrices lineales. Incluso se parte de un abanico de "opciones estratégicas" entre las cuales el estratega sólo debe elegir y continuar con su posterior implementación.

No se puede seguir desconociendo las relaciones no lineales y las propiedades emergentes de las organizaciones, que de alguna manera son las que determinan la acción. Así como tampoco persistir en la idea de diseñar organizaciones desde un pensamiento objetivo donde no tienen influencia los actores que intervienen. Pero desafortunadamente se continúa perdiendo de vista que la "organización no es un objeto, una cosa invariante independiente de su observador. Por el contrario expresa a la vez, inseparablemente, la acción, el actor, y la transformación temporal del actor" (Le Moigne, 1999, 76).

\subsubsection{Cambio en el enfoque de pensamiento estratégico: del conflicto a la articulación}

Derivado de influencia militar en el campo del pensamiento estratégico en la gestión, la idea de estrategia se ha enmarcado primordialmente en la de competencia, incluso en la de conflicto. Se parte de la idea de la existencia de muchos intereses en juego, la mayoría contradictorios que no encuentran una vía de encuentro. El conflicto ha quedado limitado a la idea de confrontación, rivalidad, oposición y el mercado suele ser la mejor representación del campo de batalla. Lo que de alguna manera ha conducido a la adopción de mecanismos de acción desde el pensamiento estratégico, donde el fin: abatir al contrincante justifica los medios.

A pesar del arraigo de estas representaciones, promovidas por abundante literatura académica del campo, ha surgido una forma distinta de concebir la acción y las dinámicas en el mercado, por tanto conceptos como negociación, mediación y cooperación entran en el escenario del pensamiento estratégico. Las organizaciones pueden consolidarse a través de estrategias que permiten no solo el desarrollo individual, sino también el de más integrantes del medio. Se reconoce que la agresividad del entorno también se puede enfrentar con esfuerzos cooperativos o solidarios, que permite la búsqueda en conjunto de propósitos organizacionales o empresariales, donde el desarrollo colectivo se convierte en un aspecto determinante, no el de permanecer a costa de eliminar al otro.

Esta idea de mediación, también involucra el interior de las organizaciones. En esa medida el pensamiento estratégico debe permitir la articulación de los diversos intereses que están en juego en su dinámica interna (colaboradores, accionistas, clientes, proveedores, sociedad), que no necesariamente son opuestos. Se busca la construcción de un proyecto colectivo, por medio del dialogo donde se acoplen las distintas percepciones e intereses a un objetivo común. No sólo con el ánimo de no entorpecer el logro de los propósitos organizacionales que se establecen, sino de generar a través de un dialogo productivo nuevos estadios de acción e innovación (Pérez, 2007).

\subsubsection{Cambio en las herramientas: nuevos instrumentos para hacer pensar estrategias en un mundo complejo y dinámico}

Una simple revisión de las técnicas y herramientas en las que tradicionalmente se ha apoyado el 
pensamiento, permitiría ver que fueron concebidos para una época en la que se pensaba que el futuro era planificable y de alguna manera predecible. La complejidad actual no puede ser abordada exclusivamente con los modelos y herramientas con que se miraron los problemas en el pasado (Manucci, 2006), se requieren métodos capaces de describir las interacciones, las no-linealidades, la policausalidad, los flujos, las relaciones para poder actuar en ellas. Se necesitan instrumentos y herramientas diseñadas bajo la lógica de la flexibilidad y la indeterminación donde no prime el equilibrio y el control.

Son muy pocos los desarrollos metodológicos, desde la perspectiva de la complejidad, que han surgido directamente de las ciencias económicas, pero otras áreas del conocimiento como la teoría de redes, las neurociencias, las matemáticas de los sistemas nolineales, la lógica difusa, las ciencias de la complejidad, han logrado desarrollar métodos e instrumentes capaces de comprender dicha complejidad sin reducirla. Es el momento para que el pensamiento estratégico asuma el reto de hacer uso de esos desarrollos.
Una propuesta metodológica en la perspectiva de la complejidad diseñada para el pensamiento estratégico ${ }^{16}$, es "la estrategia de los cuatro círculos" del Profesor Manucci (2006). Se trata de una metodología compleja basada en cuatro procesos (percepciones, posiciones, relaciones, acciones) que permiten transitar, proyectar, integrar recursos y generar alternativos de acción para participar en la complejidad del entorno. Los cuatro círculos, como denomina el autor a los procesos, conforman una estructura de acción mediada por su interrelación $e$ influencia mutua. Las percepciones, las posiciones, las relaciones y las acciones operan al mismo tiempo sin un orden predeterminado, ya que lo ordinal se pierde en función de la emergencia y cobra importancia cualquier modificación en cada uno de los círculos que afectará a los demás, ampliando la capacidad de respuesta (Manucci, 2006).

Desde la perspectiva de interdependencia de la metodología, las percepciones influyen sobre las posiciones; generando un territorio de acción más amplio, donde a su vez surgen mayores perspectivas de desarrollo, y al ampliarse las perspectivas se enriquece el espacio de acción definido para la or-

Tabla 3. Modelo de los cuatro círculos ${ }^{15}$

\begin{tabular}{|c|c|c|c|}
\hline CÍRCULO & DEFINICIÓN & OBJETIVO DE TRABAJO & EJE DE TRABAJO \\
\hline Percepciones & $\begin{array}{l}\text { Define el territorio de acción corporativo a través } \\
\text { de un conjunto de factores racionales, emotivos y } \\
\text { conductuales. }\end{array}$ & $\begin{array}{l}\text { Mantener la operatividad del territorio de acción } \\
\text { a través de una redefinición constante de los } \\
\text { límites. }\end{array}$ & Vivencia \\
\hline Posiciones & $\begin{array}{l}\text { Define el propósito y las hipótesis alternativas de la } \\
\text { intervención basada en la imagen del contexto. }\end{array}$ & $\begin{array}{l}\text { Diseñar hipótesis dinámicas de intervención } \\
\text { que mantenga alternativas en la definición de } \\
\text { rumbos corporativos. }\end{array}$ & Propósito \\
\hline Relaciones & $\begin{array}{l}\text { Define la estructura de recursos materiales, humanos y } \\
\text { técnicos para participar en la trama del entorno. }\end{array}$ & $\begin{array}{l}\text { Conformar una red de recursos que permita } \\
\text { ampliar el territorio de acción y enriquecer la } \\
\text { operatividad de las acciones. }\end{array}$ & $\begin{array}{l}\text { Integración para diseñar } \\
\text { oportunidades }\end{array}$ \\
\hline Acciones & $\begin{array}{l}\text { Define el modo de participar y la dinámica de las } \\
\text { decisiones para generar y gestionar las acciones. }\end{array}$ & $\begin{array}{l}\text { Definir un modo de participar en la dinámica } \\
\text { del contexto basado en el diseño y la gestión de } \\
\text { vínculos estratégicos. }\end{array}$ & Valor \\
\hline
\end{tabular}

15 Fuente: Manucci, (2006, 134).

16 Sin desconocer que el autor se apoyó para su desarrollo en otras ciencias. 
ganización. Las relaciones por su parte tienen que ver con la integración de los recursos, a mayor integración de los recursos, mayor riqueza para ampliar las percepciones y posiciones. De esta manera las acciones dejan de ser meras respuestas estereotipadas ante determinados eventos, para alcanzar un nivel cada vez mayor de complejidad y de profundidad a partir del desarrollo de vínculos estratégicos con los se moviliza la organización (Manucci, 2006, 90-124).

Está dinámica de los cuatro círculos, permite que la organización genere un proceso de "aprendizaje sobre sus acciones, que pueda innovar incorporando información a su percepción, perspectivas a su posición y recursos a sus relaciones y mantener su unidad de intervención como una estructura flexible que se autorganiza frente a los sucesos cotidianos" (Manucci, 2006, 131). La metodología se sirve a su vez de tres herramientas que posibilitan su operacionalización: i) Análisis de factores estratégicos: diseño y gestión de la propuesta organizacional, ii) Mapa de intervención: diseño y proyección de acciones en diferentes ámbitos estratégicos de intervención, y iii) Matriz de vínculos estratégicos: articulación del proyecto estratégico basado en cuatro matrices ${ }^{6}$ que articulan la propuesta diferencial y que conducen a la acción.

Esta propuesta transciende el razonamiento de causalidad lineal, es un abordaje alternativo al modelo mecanicista, posibilita mayor amplitud en la capacidad de análisis del contexto y de respuesta. No se presenta como una receta, porque cada organización construye su propio camino hacia el futuro, es una metodología que se adapta al proyecto estratégico de la organización, no al contrario como es habitual en las métodos tradicionales de pensamiento estratégico.

\section{Reflexión final}

A raíz de las críticas hechas por el determinismo con que se ha tratado el problema de la estrategia en las organizaciones, se genera una reflexión sobre el paradigma racional y mecanicista en el que se ha fundado. La discusión actual se orienta hacia la necesidad de configurar una perspectiva que reconozca la complejidad inherente al proceso de construcción de futuro, que reconozca la articulación de lo deliberado y lo emergente, lo incierto y lo aleatorio, así como el juego e interrelaciones de múltiples actores que intervienen.

La revisión realizada permitió identificar, que sí bien siguen siendo preponderantes las perspectivas tradicionales de la estrategia, éstas hoy son insuficientes para responder a los retos que enfrentan las organizaciones del siglo XXI. Lo que ha conducido a la emergencia de un nuevo paradigma que responde a las condiciones actuales de los procesos estratégicos en las organizaciones, así como a la evolución del campo de estudio en relación a la concepción de la estrategia (propósitos y áreas de conocimiento involucradas), a los aspectos metodológicos que la sustentan (métodos y herramientas), a los actores que intervienen en el proceso; y a los factores considerados (incertidumbre, poder, cultura, ambiente, entre otros).

De igual manera es importante señalar que la revisión de la literatura académica permitió rastrear las escuelas o corrientes de pensamiento que se han establecido por diversos autores con el ánimo de diferenciar las posturas que se tiene de los propósitos, su proceso y herramientas. La propuesta de las distintas taxonomías devela como son entendidos dos procesos que se han definido como fundamentales en el campo: la formulación y la implementación. Desde distintos enfoques se conciben como dos procesos que van de la mano, pero que se generan en momentos distintos, por ende se separa el pensamiento de la acción. Mientras otras posturas logran integrarlos en la práctica, considerando que son procesos inseparables, buscando una construcción compleja del mismo.

De manera central, el cambio de paradigma que se le reclama al campo, manifiesta el agotamiento de

14 Matriz de propuesta diferencial, matriz funcional de públicos, matriz de evaluación y matriz de acciones estratégicas (Manucci, 2006). 
la perspectiva tradicional e implica no solo la identificación de nuevas aproximaciones teóricas y metodológicas, como las que surgen desde el paradigma de la complejidad, sino también el acercamiento a áreas de conocimiento distintas de las ciencias económicas. Se presenta entonces el avance en el campo (complejidad y estrategia), poco abordado aún en nuestro contexto, pero que se constituye en un desafío por su pertinencia para actuar en ambientes inestables, inciertos, dinámicos, que deben reconocer, aprehender y comprender los estrategas para poder gestionar las organizaciones.

El llamado final es a reflexionar sobre nuevo paradigma en el campo del pensamiento estratégico, a desplazar los esquemas tradicionales que han imperado, así como a poner de manifiesto la urgencia de su comprensión como un mecanismo de acción desde la complejidad, asociado más con la idea de lo flexible o cambiante, que con lo formalizado, programado o predeterminado, dándole preponderancia a los procesos de aprendizaje y de adaptación. Lo que realmente conduce a la creatividad $e$ innovación para que el futuro de la organización pase de ser anticipado a ser creado y se le dé cabida a lo imprevisto y emergente.

Pensar en una nueva perspectiva para el pensamiento estratégico debería ser una opción ineludible, preocupación de todos los que hacen uso de él, en las distintas áreas de aplicación. Pero de manera particular preocupación de las escuelas de administración, quiénes por su razón de ser deben promover nuevas aproximaciones teóricas y metodológicas, para formación, investigación y consultoría, acordes a las condiciones del entorno. Desde las Universidades se gesta el cambio y la materialización de las acciones necesarias para que la consolidación de una nueva perspectiva de abordaje en el campo de la estrategia empresarial sea pertinente para el contexto colombiano.

\section{Referencias}

Andrews, K. (1971). The concept of Corporate Strategy. Homewood, IL: Irwin editions.

Ansoff, I. (1965). Corporate Strategy. New York: McGraw-Hill.

Ansoff, I. (1987). The emerging paradigm of strategy behavior. En: Strategic Management Journal, 8: 501-515.
Ansoff, I. \& Sullivan, P. (1993). Empirical proof of the paradigms theory of strategy success behaviors of environmental serving organizations. En: International Review of strategy management; Vol, 173-203.

Berelson, B. (1952). Content Analysis in Communication Research. New York: Free Press.

Boyd, B., Gove, S. \& Hitt, M. (2005). Consequences of measurement problems in strategic management research. En: Strategic Management Journal, 26 (4), 367-375.

Bracker, J. (1980). The Historical Development of the Strategic Management Concept. En: Academy of Management Review, 5: 219-224.

Bruner, J. (1968). El Proceso de la Educación. Colecciones Manuales UTEHA. En: Serie Educación, 17: 89 - 93.

Carrance, F. (1986). Les Outils de planification stratégique auconcret. Tesis doctoral. Ecole Polytechnique, Paris.

Chandler, A. (1962). Strategy and structure: Chapters in the History of the Industrial Enterprise. USA: Cambridge, MA: MIT Press.

Cole, A. (1959). Business Enterprise in Its Social Setting. Cambridge, USA: Harvard University Press.

Creswell, J. (2003). Research design: qualitative, quantitative, and mixed method approaches ( $2^{\mathrm{a}}$ ed.). London: SAGE.

Delgado, C. \& Sotolongo, P. (2006). La complejidad y el nuevo ideal de racionalidad. La revolución contemporánea del saber y la complejidad social. Hacia unas ciencias sociales de nuevo tipo. Buenos Aires: Colección Campus Virtual CLACSO.

Dewey, J. (1989). Cómo pensamos. Nueva exposición entre la relación entre pensamiento reflexivo y proceso educativo. Barcelona: Paidós.

Etkin, J. \& Schvarstein, L. (2005). Identidad de las organizaciones: invarianza y cambio. Buenos Aires: Editorial Paidós.

Etkin, J. (2003). Gestión de la complejidad en las organizaciones. Las estrategias frente a lo imprevisto y lo impensado. Buenos Aires: Ediciones Granica.

Ezzamel, M. \& Willmott, H. (2004). Rethinking Strategy: Contemporary Perspectives and Debates. En: European Management Review, (1): 43 - 48.

Feurer, R. \& Chaharbaghi, K. (1995). Strategy Development: Past, Present and Future. En: Management Decision, 33 (6): 11 - 21.

French, S. (2009). Cogito Ergo Sum: Exploring Epistemological Options for Strategic Management, En: Journal of Management Development, 1 (28): 18 - 37.

Fréry, F. (2006). The fundamental dimensions of strategy. En: MIT Sloan management review, 48 (1): 71 - 75.

Furrer, O., Thomas, H. \& Goussevskaia, A. (2007). The structure and evolution of the strategic management field: A content analysis of 26 years of strategic management research. En: International Journal of Management Reviews, Vol. 10 (1): 1 - 23.

Gratton, C. \& Jones, I. (2004). Research methods for sport studies. London: Routledge.

Hamel, G. \& Prahalad, C.K. (1994). Competing for the Future. Boston: Harvard Business School Press.

Harper, S. \& Lynch, J. (1992).Estrategia empresarial. Buenos Aires: Editorial El Ateneo.

Hart, S. (1992). An integrative framework for strategy-making processes. En: Academy of Management: 327-352.

Knight, K. (1967). A Descriptive Model of the Intra-Firm Innovation Process. En: Journal of Business, 40 (4): 478-496.

Krippendorf, K. (1990). Metodología de análisis de contenido. 


\section{UNA APROXIMACIÓN AL CAMPO DE ESTUDIO DEL PENSAMIENTO ESTRATÉGICO DESDE LAS PUBLICACIONES ACADÉMICAS: \\ DE LO PREDECIBLE A LO EMERGENTE}

Teoría y Práctica. Buenos Aires: Paidós Comunicación.

Le Moigne, J. (1997). La incoherencia epistemológica de las ciencias de la gestión. En: Cuadernos de Economía No. 26. Universidad Nacional de Colombia.

Lindblom, C. (1959). The Science of Muddling Through. En: Public Administration Review: 79-88.

López, P. \& Mariño, A. (2010). Hacia una evolución en el campo del conocimiento de la disciplina administrativa: de la administración de empresas a la gestión de organizaciones. En: Revista Facultad de Ciencias Económicas, XVIII (2): 75-93.

Manucci, M. (2006). La estrategia de los cuatro círculos. Diseñar el futuro en la incertidumbre del presente. Bogotá: Norma GE.

Martinet, A. (1996). Pensé strategique et rationalités: Un examen épistémologique. En: Papier de recherché numéro 23. Lyon: Institut d' Administrátion des Enterprises.

Martinet, A.(1997). Planification Stratégique. En: Simon, Y. \& Joffre, P (comps.) Encyclopédie de Gestión (2249 - 2265). Paris: Economica, Tomo II.

Menguzzatto, M. \& Renau.J. (1991).La dirección estratégica de la empresa. Barcelona. Editorial Ariel.

Mintzberg, H. (1990). The Design School, Reconsidering the basic premises of Strategic Management. En: Strategic Management Journal, 11: 171 - 195.

Mintzberg, H. (1994). The Rise and Fall of Strategic Planning: Reconceiving Roles for Planning, Plans, Planners. Free Press: New York.

Mintzberg, H., Ahlstrand, B. \& Lampel, J. (1998). Strategy Safari: A Guided Tour Through The Wilds of Strategic Management. USA: The free Press.

Mintzberg, H., Ahlstrand, B. \& Lampel, J. (1998). Strategy Safari: A Guided Tour Through The Wilds of Strategic Management. USA: The free Press.

Morin, E. (1993). El Método I. La Naturaleza de la Naturaleza. Madrid: Ed. Cátedra S.A.

Morin, E. (2001). Introducción al Pensamiento Complejo. Barcelona: Editorial Gedisa.

Morin, E. (2007). La epistemología de la complejidad. El paradigma ecológico en las Ciencias Sociales. Barcelona: Icaria Editorial.

Morrisey, G. (1997). Pensamiento estratégico. México: Prentice Hall.

Navarro, J. (2000). Gestión de organizaciones: Gestión del caos. En: Revista Dirección y Organización, Universidad Politécnica de Madrid, 23: 136 - 145

Nerur, P., Rasheed, A. \& Natarajan, V. (2008). The Intellectual Structure of the Strategic Management Field: an Author Co-citation Analysis. En: Strategic Management Journal, 29, (319-336).

Ohmae, K. (1983). La mente del estratega: el triunfo de los japoneses en el mundo de los negocios. México: McGraw Hill.

Ohmae, K. (1995). The End of Nation State. The Rise of Regional Economies. New York: Free Press Paperbacks.

Pérez, R. (2004). La nueva teoría estratégica: Estado de la cuestión. Presentado en el II Encuentro Iberoamericano sobre estrategias de comunicación.
Pérez, R. (2007). Las siete señas de identidad de la nueva teoría estratégica. En: FISEC-Estrategias, 3 (7): 6-27.

Pettigrew, A., Thomas, H. \& Whittington, R. (2001). Strategic Management: The Strengths and Limitations of a Field. En: Handbook of Strategy and Management (3-30).

Porter, M. (1980) Competitive Strategy: Techniques for Analyzing Industries and Competitors. New York: Free Press.

Prahalad, C. \& Hamel, G. (1994). Strategy As A Field Of Study: Why Search For A New Paradigm? Strategic Management Journal, 15: 5-16.

Quinn, J. B. (1980). Strategies for Change: Logical Incrementalism. USA: Richard D. Irwin, Inc.

Ramanantsoa, B. (1997). Stratégie. En: Simon, Y. \& Joffre, P. Encyclopédie de Gestión. (3026-3042). Paris: Economica, Tomo III.

Ramos, A. \& Ruiz, J. (2004). Changes In The Intellectual Structure Of Strategic Management Research: A Bibliometric Study Of The Strategic Management Journal, 1980-2000. En: Strategic Management Journal, 25: 981-1004.

Román, O. (2010). El pensamiento estratégico. Una integración de los sentidos con la razón. En: Revista Científica Guillermo de Ockham, 8. (2): 23-36.

Ronda, G. \& López, E. (2008). Empleo del Análisis de Redes Sociales para el estudio de la estructura de la relación entre definiciones del concepto estrategia elaboradas entre los años 1962 y 2003. En: Revista hispana para el análisis de redes sociales, 14 (9).

Schendel, D.E. \& Hoffer, C. (1978). Strategic Management: A New View of Business Policy and Planning. Boston: Little Brown.

Schumpeter, J. (1947). The Creative Response in Economic history. USA: Journal of Economic History.

Selznick, P. (1957). Leadership in Administration: a Sociological Interpretation. Evanston IL: Row, Peterson.

Sotirin, P. \& Tyrell, M (1998). Wondering about critical Management studies. En: Management Communication Quarterly, 2: 303-336.

Stacey, R. (2000). Strategic Management and Organizational Dynamics: The Challenge of Complexity. London: Prentice Hall.

Tabatorny, P. \& Jarniou, P. (1975). Les systemes de Gestion: politiqueset structures. París: PUF.

Tsoukas, H. \& Knudsen, C. (2002). The Conduct Of Strategy Research. En: Handbook Of Management \& Strategy. London: Sage Publications.

Van der Heijden, K. (1998). Escenarios. El arte de prevenir el futuro. México: Panorama.

Whittington, R. (2002). What is strategy and Does it matter? London: Routledge.

Wilson, I. (1994). Strategic planning isn't dead it change. En: Long range planning, 27 (4): 12-24. 